\title{
Simultaneous Control of Shape and Properties of AZ31 Magnesium Alloy Sheets by Incremental Forming
}

\author{
Masaaki Otsu, Yusuke Kai* and Kazuki Takashima \\ Graduate School of Science and Technology, Kumamoto University, Kumamoto 860-8555, Japan
}

In this study, simultaneous control of shape and hardness of AZ31 magnesium alloy sheets by incremental forming process was proposed. Influences of working temperature, giving strain and heat treatment temperature on hardness were investigated. AZ31 magnesium alloy sheets were formed into pyramidal shape by incremental forming process at $100^{\circ} \mathrm{C}$ and $200^{\circ} \mathrm{C}$. Major strains given to the pyramidal faces were $0.1,0.2$ and 0.3. After forming, heat treatment was carried out at various temperatures. Combination of final shape and total equivalent plastic strain were changed by multi-step forming and hardness distribution was measured. From the experimental results, it was found that when heat treatment was done at $200^{\circ} \mathrm{C}$ for $10 \mathrm{~min}$ after forming at $200^{\circ} \mathrm{C}$, hardness of the specimen became higher than that of as received one. When heat treatment was carried out at $175^{\circ} \mathrm{C}$ for 60 min after forming at $100^{\circ} \mathrm{C}$, hardness of the specimen also increased. In the case of multi-step forming, strain was accumulated at forming temperature of $100^{\circ} \mathrm{C}$ and hardness increased, but not at the forming temperature of $200^{\circ} \mathrm{C}$. By multi-step forming at $100^{\circ} \mathrm{C}$, asymmetric hardness distribution with symmetric shape was realized and simultaneous control of shape and hardness was succeeded. [doi:10.2320/matertrans.MC2007102]

(Received October 18, 2007; Accepted February 4, 2008; Published April 25, 2008)

Keywords: simultaneous control, shape, hardness, incremental forming

\section{Introduction}

In sheet metal forming, flat metal sheets are formed into desirable three-dimensional shape. Strain distribution of formed sheet is almost determined by formed shape, though strain distribution can control certainly by employing multistep forming. Strain distribution governs product's mechanical properties such as hardness in as formed state and microstructures such as grain size after heat treatment. If forming shape and strain distribution were given independently during one forming process, products having desirable shape and distribution of mechanical properties and microstructure would be manufactured.

Incremental forming process is one of sheet metal forming methods without punch and dies. In this process, only a simple stick tool is used for forming and the tool is moved along the contour lines of three-dimensional shape of product. Since the sheet is formed at only small region in this process, forming limit is improved comparing with the conventional stamping process. ${ }^{1-4)}$ By employing incremental forming process, it is easy to flatten the formed sheet although it is very difficult by the conventional stamping methods. ${ }^{5}$ ) Thus, it is possible to deform the reversed sheet already formed. This means that shape and strain distributions can be controlled simultaneously and independently by introducing multi-step forming for forming several intermediate shapes.

In this study, simultaneous control of shape and mechanical properties by incremental forming were aimed, and effects of accumulated equivalent plastic strain, working temperature and heat treatment conditions on hardness were investigated.

*Graduate Student, Kumamoto University

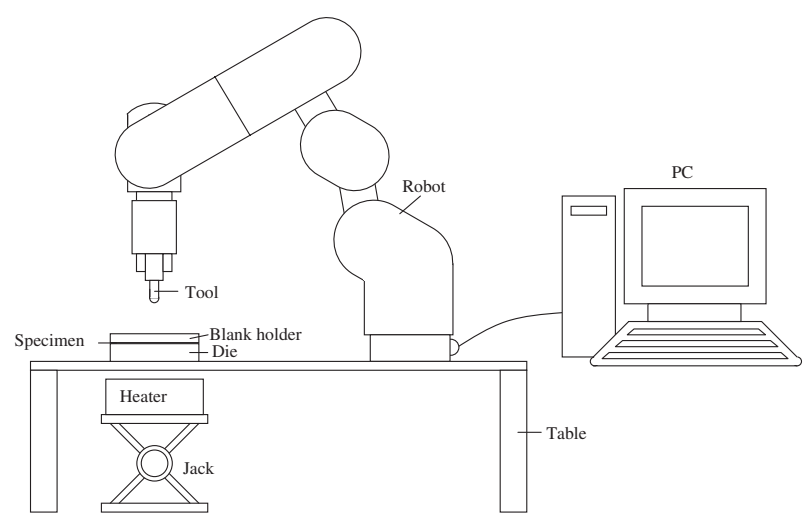

Fig. 1 Schematic illustration of experimental equipment.

\section{Experimental Method}

\subsection{Equipment}

Figure 1 shows a schematic illustration of experimental equipment. Specimen sheets were fixed to a blank holder and dies, and deformed by a stick tool having a hemispherical head with a radius of $3 \mathrm{~mm}$ mounted on a six-axis robot arm. The motion of the forming tool was controlled numerically by a personal computer. The specimen sheet was heated by a resistant heater and working temperature was controlled by adjusting the position of the heater using a jack. The temperature of the specimen sheet was measured by an infrared thermometer.

\subsection{Conditions}

Experimental conditions for incremental forming are shown in Table 1. AZ31B-O magnesium alloy sheets were used for specimens. An optical micrograph of as received one is shown in Fig. 2, and the average grain size was $8.8 \mu \mathrm{m}$. The shape of the sheets was a right square of $100 \mathrm{~mm} \times$ 
Table 1 Experimental conditions for incremental forming.

\begin{tabular}{cc}
\hline Dimensions of specimens $/ \mathrm{mm}$ & $100 \times 100 \times 0.4$ \\
\hline Forming shape & Pyramidal \\
\hline Base size of forming pyramid $/ \mathrm{mm}$ & $60 \times 60$ \\
\hline Forming pitch $/ \mathrm{mm}$ & 0.5 \\
\hline Working temperature $/{ }^{\circ} \mathrm{C}$ & 100,200 \\
\hline Heat treatment temperature $/{ }^{\circ} \mathrm{C}$ & $150-250$ \\
\hline Heat treatment time $/ \mathrm{min}$ & $5-60$
\end{tabular}

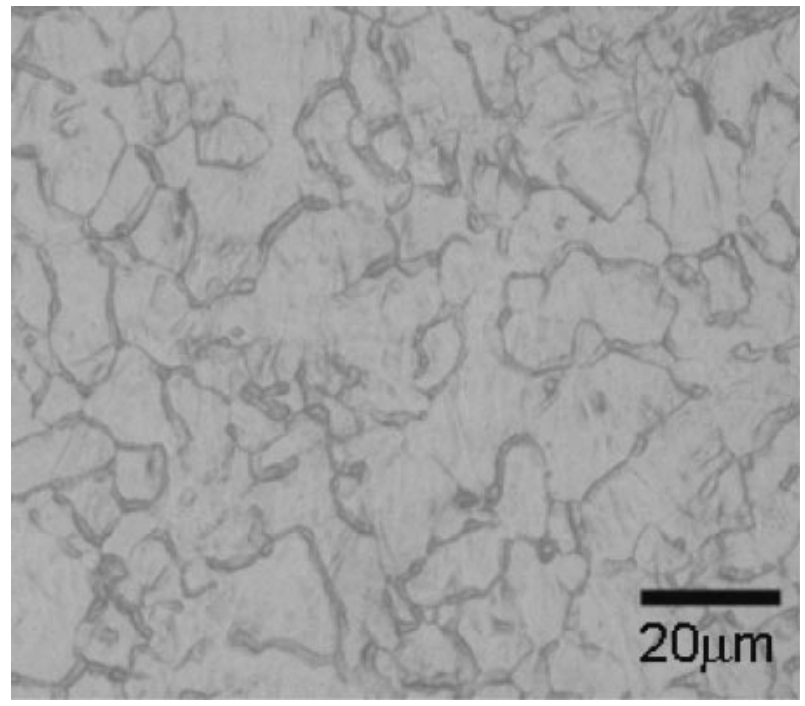

Fig. 2 Optical micrograph of as received AZ31-O sheet.

$100 \mathrm{~mm}$ and thickness was $0.4 \mathrm{~mm}$. Formed shape was pyramidal with a square base of $60 \mathrm{~mm} \times 60 \mathrm{~mm}$. By changing the height of the pyramid, the strain of pyramidal faces was controlled. Working temperature was $100^{\circ} \mathrm{C}$ and $200^{\circ} \mathrm{C}$. Heat treatment after forming was also carried out at a temperature of $150-250^{\circ} \mathrm{C}$ which is near the recrystallization temperature. ${ }^{6}$

\subsection{Procedure}

Procedure of moving the tool is expressed in Fig. 3. First, the tool was pushed into the sheet for $h \mathrm{~mm}$ and then moved along the square path of $60 \mathrm{~mm} \times 60 \mathrm{~mm}$ first. After moving along the square path, the tool was moved to the $0.5 \mathrm{~mm}$ inner and $h \mathrm{~mm}$ deeper position, linearly. This forming process was repeated until pyramidal shape was finished.

To measure the strain of sheet, the circle grid method was employed. Estimated strain from forming condition and measured strain were obtained beforehand and calibration was performed. Forming was carried out for giving major strain of 0.1 and 0.2 at working temperature of $100^{\circ} \mathrm{C}$, and major strain of $0.1,0.2$ and 0.3 at $200^{\circ} \mathrm{C}$. After forming, heat treatment was carried out at $150-250^{\circ} \mathrm{C}$ for $60 \mathrm{~min}$ in a muffle furnace. Observation of microstructure by optical microscope and measurement of vickers hardness were done for as formed and heat treated sheets. Hardness test was carried out for seven times and the average value was calculated from the five data except the minimum and the maximum values.
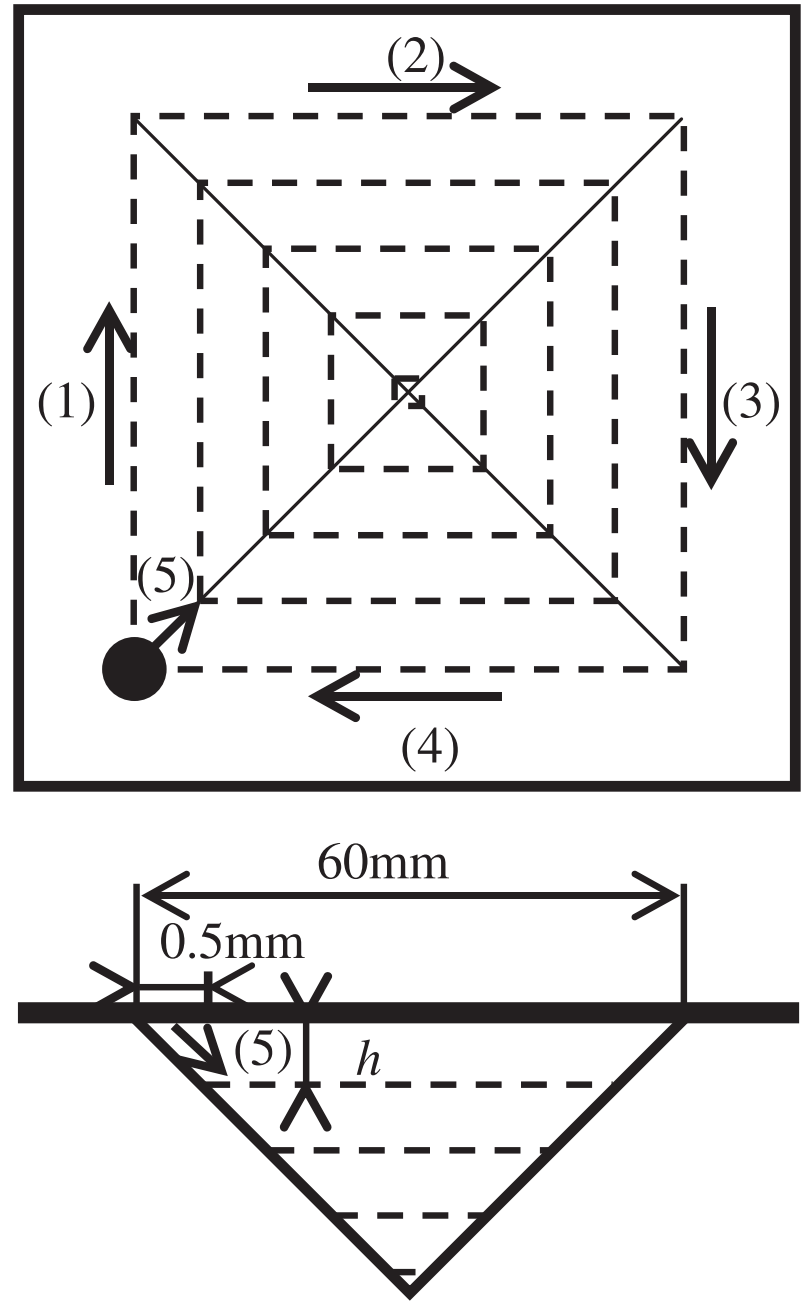

Fig. 3 Procedure of moving tool.

In this study, two types of forming, single step forming and multi-step forming, were performed. In single step forming, the final shape was formed with only one step. In multi-step forming, the sheet was deformed into an intermediate shape and the sheet was turned upside down as shown in Fig. 4. This process was repeated for several times and then, the final shape was formed.

\section{Results}

\subsection{Single step forming}

Relationship between hardness and heat treatment temperature after forming at $100^{\circ} \mathrm{C}$ is illustrated in Fig. 5. In the case of working temperature of $100^{\circ} \mathrm{C}$, hardness increased by forming, however, there were no significant difference between the cases that major strain were 0.1 and 0.2 . Although hardness decreased as heat treatment temperature became high, it increased a little at $175^{\circ} \mathrm{C}$. From the optical microscope observation, many twin crystals were found but recrystallization did not occurred. When heat treatment temperature was higher than $225^{\circ} \mathrm{C}$, hardness of formed one became lower than that of as received one due to the recrystallization.

In Fig. 6, relationship between hardness and heat treatment temperature after forming at $200^{\circ} \mathrm{C}$ is shown. Hardness of as 
(i)

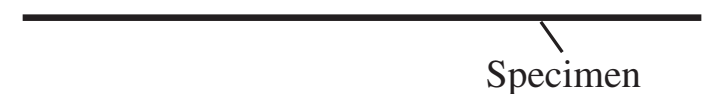

(ii)

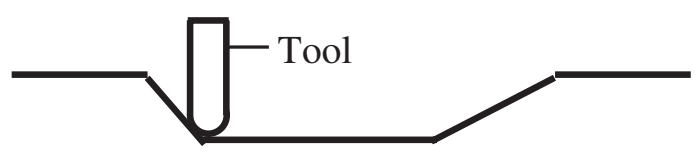

(iii)
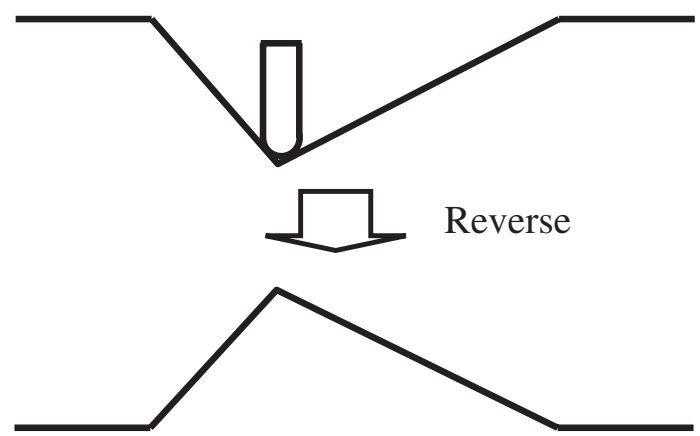

(iv)

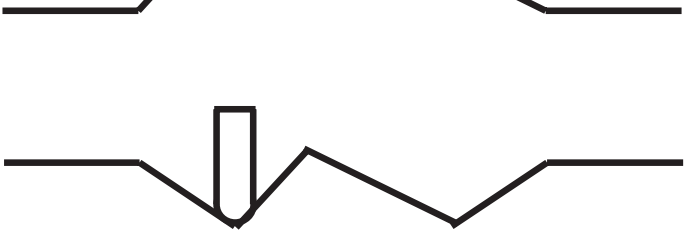

(v)

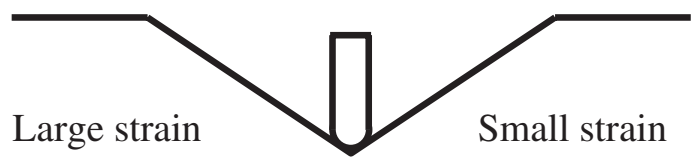

(vi)

Large strain

Fig. 4 Schematic illustration of multi-step forming.

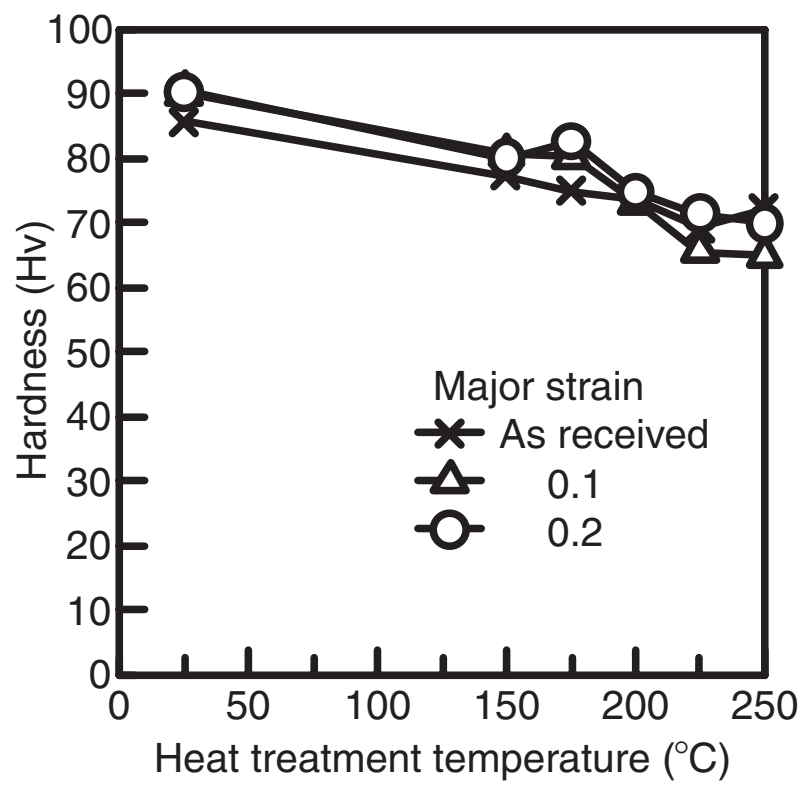

Fig. 5 Hardness of sheets formed at $100^{\circ} \mathrm{C}$ after heat treatment.

received sheets decreased as heat treatment temperature was elevated, however, that of formed ones at $200^{\circ} \mathrm{C}$ did not change very much. When heat treatment was carried out at $200^{\circ} \mathrm{C}$, hardness increased and, especially, that with major

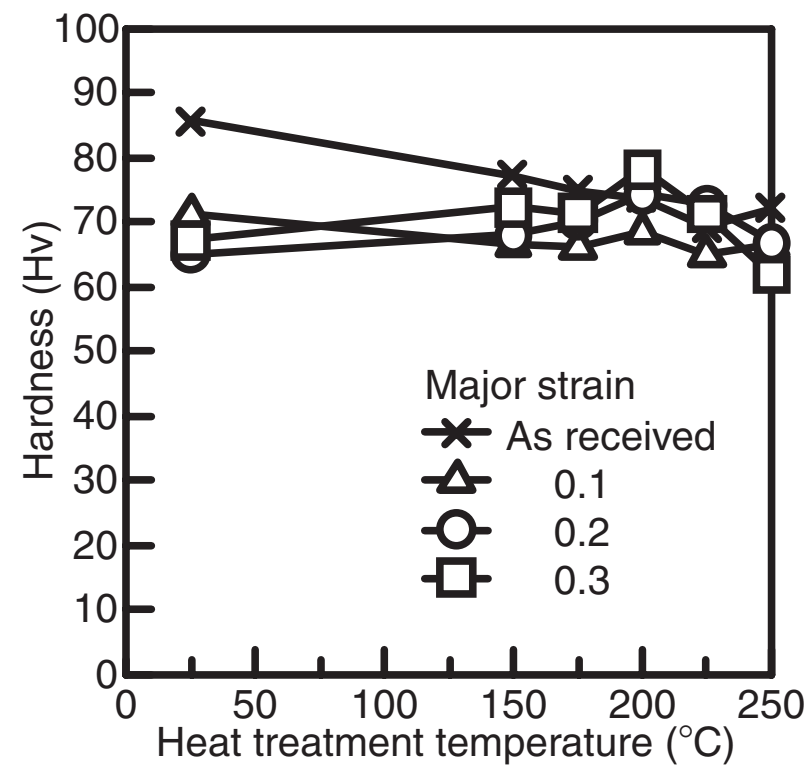

Fig. 6 Hardness of sheets formed at $200^{\circ} \mathrm{C}$ after heat treatment.

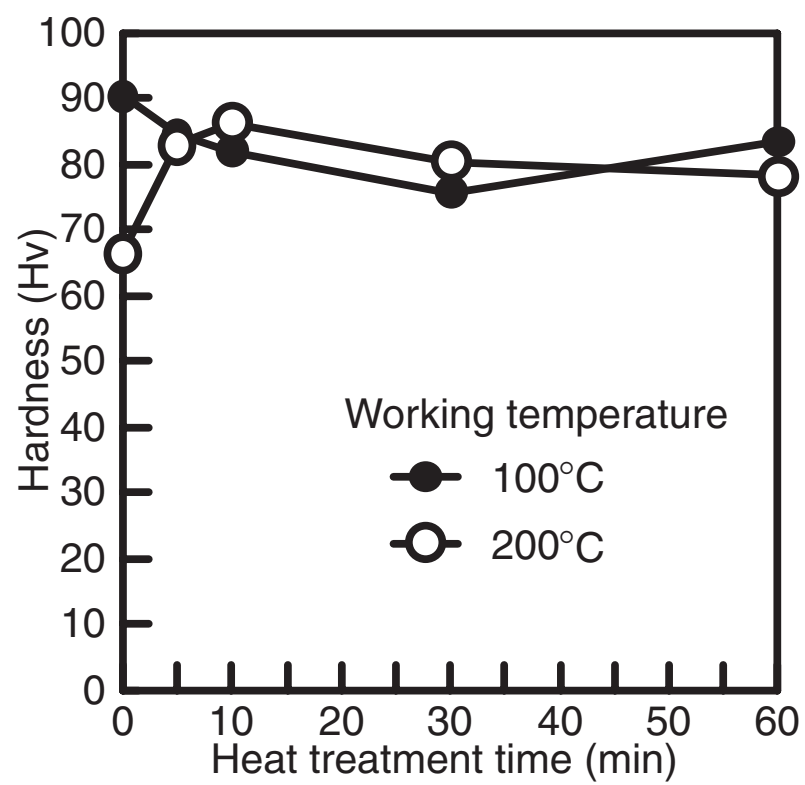

Fig. 7 Effect of heat treatment time on hardness.

strain of 0.3 became higher than that of as received one. In addition, hardness became maximum when heat treatment time was 10 min as shown in Fig. 7 expressing the effect of heat treatment time on hardness. In all heat treatment temperature case, recrystallization was observed.

\subsection{Multi-step forming}

Hardness of sheet formed into different shape with same equivalent strain at $100^{\circ} \mathrm{C}$ is plotted in Fig. 8. The final shape is expressed by the major strain. Equivalent strain was fixed to 0.35 . Although hardness decreased if heat treatment was carried out, hardness was almost equal when the final shapes were different. This means that the forming was succeeded for different shape under constant hardness.

Hardness of sheet formed into same shape with different equivalent strain at $100^{\circ} \mathrm{C}$ is illustrated in Fig. 9. As 


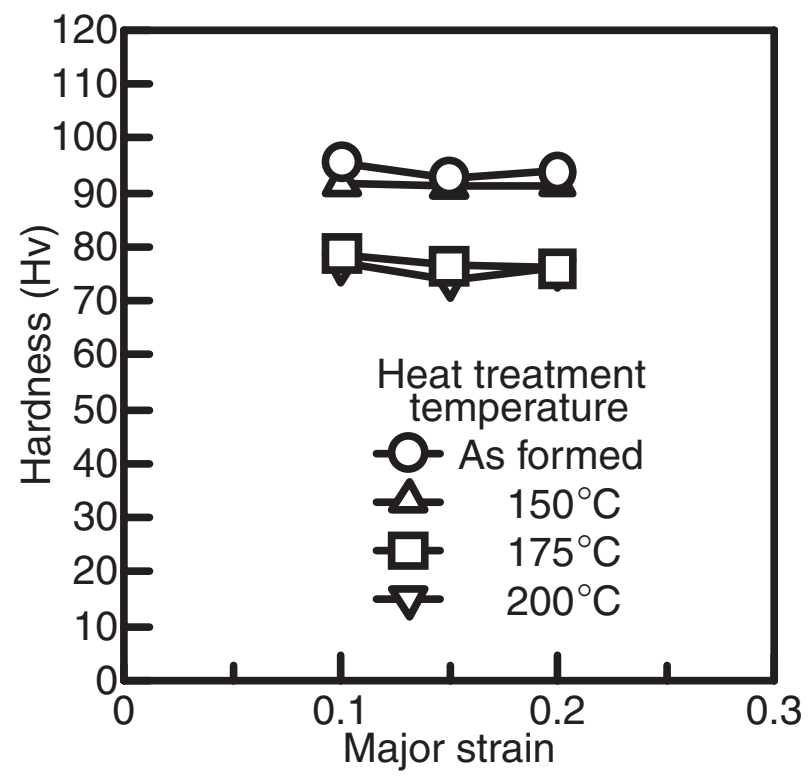

Fig. 8 Hardness of sheet formed at $100^{\circ} \mathrm{C}$ for different shape with same equivalent strain.

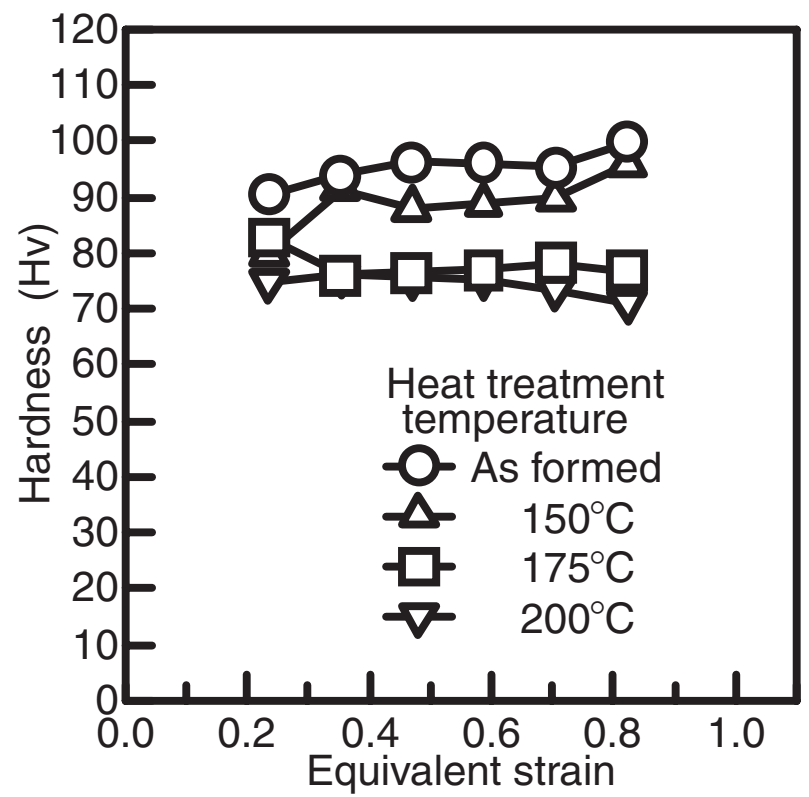

Fig. 9 Hardness of sheet formed at $100^{\circ} \mathrm{C}$ for same shape with different equivalent strain.

equivalent strain increased under same final shape, hardness slightly increased. This means that hardness was changed although the final shape did not change. The difference between minimum and maximum hardness was largest when heat treatment temperature was $150^{\circ} \mathrm{C}$. From Figs. 8 and 9, the final shape and hardness were controlled simultaneously. Hardness was decreased when heat treatment was carried out.

Next, forming was performed at $200^{\circ} \mathrm{C}$ and hardness for the cases of different shape with same equivalent strain and same shape with different equivalent strain was investigated. Figure 10 shows the relationship between hardness and the final shape with same equivalent strain of 0.35 . After heat treatment at $200^{\circ} \mathrm{C}$ for $10 \mathrm{~min}$, hardness became higher than

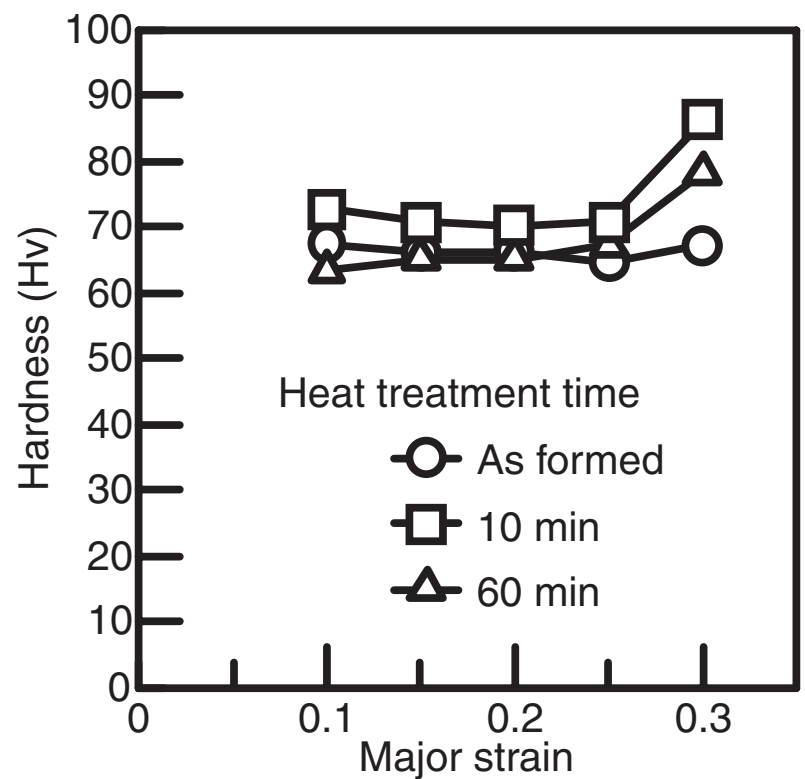

Fig. 10 Hardness of sheet formed at $200^{\circ} \mathrm{C}$ for different shape with same equivalent strain.

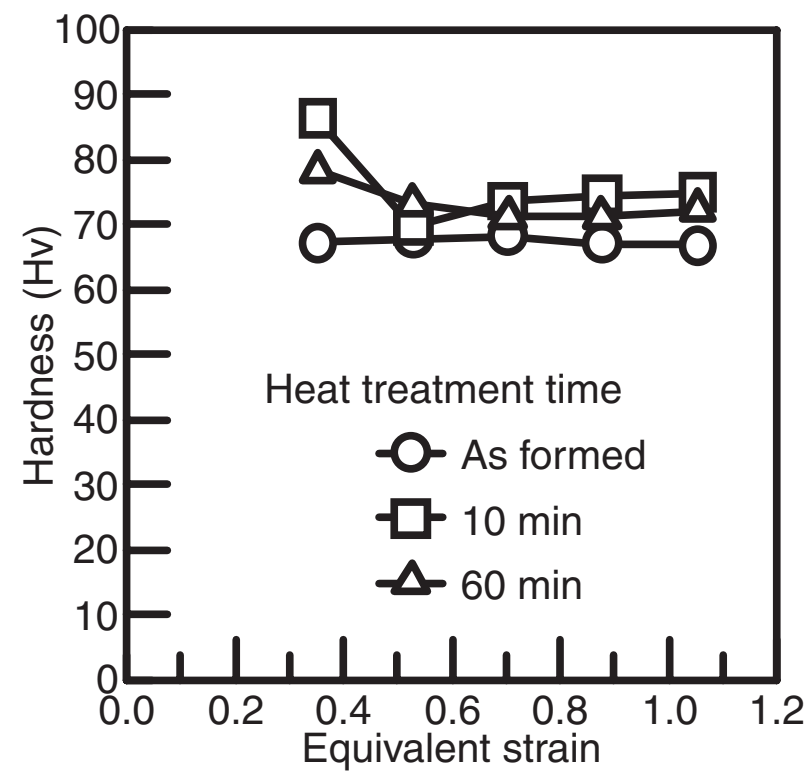

Fig. 11 Hardness of sheet formed at $200^{\circ} \mathrm{C}$ for same shape with different equivalent strain.

that of as formed one. In the case which major strain was 0.3 , that is single step forming, hardness became much higher by employing heat treatment. However, in multi-step forming case, hardness was almost constant even if forming shape was changed. Since the final shapes were different and hardness of as formed sheet was constant in multi-step forming, hardness could not be controlled.

The result of hardness of sheet formed at $200^{\circ} \mathrm{C}$ for same final shape with different equivalent strain is shown in Fig. 11. As well as the former results, hardness was highest in the case of single step forming and hardness was constant although equivalent strain was changed. So shape and hardness could not be controlled simultaneously. 


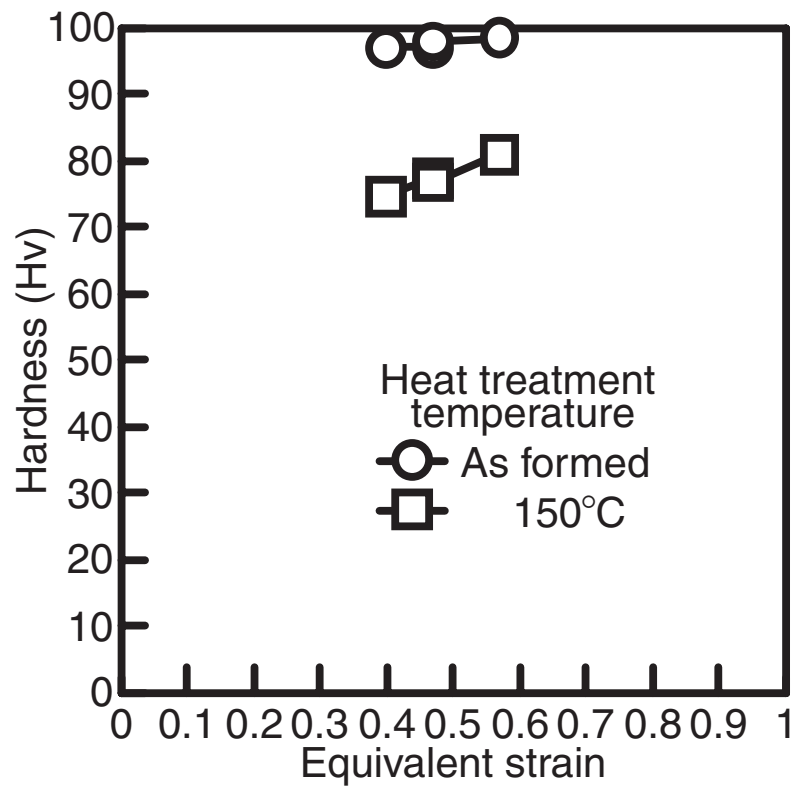

Fig. 12 Hardness of each pyramidal face formed at $100^{\circ} \mathrm{C}$ with asymmetric intermediate shape.

\subsection{Control of hardness distribution}

For an example of applying simultaneous control of shape and hardness, pyramid having symmetric shape with asymmetric hardness distribution was formed. In this case, asymmetric shape was formed as an intermediate shape and symmetric shape was formed as the final shape like shown in Fig. 4. Working temperature was $100^{\circ} \mathrm{C}$, since simultaneous control of shape and hardness was succeeded only this working temperature. Heat treatment temperature was $150^{\circ} \mathrm{C}$ to enhance the difference of the hardness. Relationship between hardness and equivalent strain is plotted in Fig. 12. Although the pyramid was a symmetric shape, hardness of each pyramidal face had different hardness as a function of equivalent strain.

When forming was carried out at $200^{\circ} \mathrm{C}$, as shown in Fig. 13, hardness of each pyramidal face was almost equal but hardness was improved by performing heat treatment at $200^{\circ} \mathrm{C}$.

\section{Conclusions}

In this study, a new forming process was proposed to realize the simultaneous control of shape and hardness by introducing multi-step forming and heat treatment after forming using incremental forming method. Effect of forming and heat treatment conditions on hardness distribution of

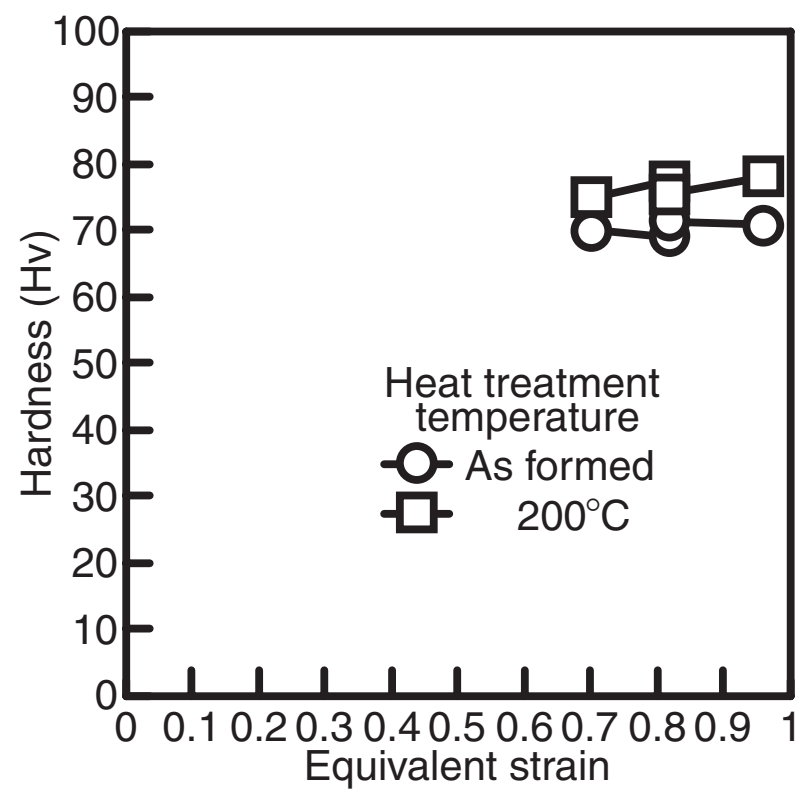

Fig. 13 Hardness of each pyramidal face formed at $200^{\circ} \mathrm{C}$ with asymmetric intermediate shape.

formed parts was examined by forming AZ31B-O magnesium alloy sheets into pyramidal shape.

(1) In single step forming, hardness of the formed sheets was improved by heat treatment at $175^{\circ} \mathrm{C}$ for $60 \mathrm{~min}$ after working at $100^{\circ} \mathrm{C}$. When heat treatment was performed at $200^{\circ} \mathrm{C}$ for $10 \mathrm{~min}$ after working at $200^{\circ} \mathrm{C}$, hardness became higher than that of as received one.

(2) In multi-step forming, simultaneous control of shape and hardness was possible when working temperature was $100^{\circ} \mathrm{C}$ but, failed when working temperature was $200^{\circ} \mathrm{C}$.

(3) Asymmetric hardness distribution with symmetric shape was formed by proposed method.

\section{REFERENCES}

1) K. Kitazawa and S. Hayashi: Trans. JSME, Part C 63-614 (1997) 36813687.

2) T. J. Kim and D. Y. Yang: Int. J. Mech. Sci. 42 (2002) 1271-1286.

3) J. Jeswiet, F. Micari, G. Hirt, A. Bramley, J. Duflou and J. Allwood: CIRP Ann. 54-2 (2005) 623-649.

4) J. M. Allwood, D. R. Shouler and A. E. Tekkaya: Key Eng. Mater. 344 (2007) 621-628.

5) K. Kitazawa and H. Hase: Proc. 55th Japanese Joint Conf. for Technol. Plasticity, (Japan Society for Technology of Plasticity, 2004) pp. 3-4.

6) The Japan Magnesium Association: Handbook of Advanced Magnesium Technology, (Kallos Publishing, 2000) pp. 137. 